\title{
RESEARCH ON P2P PLATFORMS RISK ASSESSMENT OF PRIVATE SECTOR IN CHINA BASED ON GREY RELATIONAL METHOD ${ }^{\#}$
}

\author{
*Yuhui Cai, Lingjuan Xu \\ College of Economics and Management of NUAA, \\ Nanjing, Jiangsu 211106, China \\ *Corresponding author
}

\begin{abstract}
"Supported by Humanity and Social Science Youth foundation of Ministry of Education of China "Research on prevention and control of systemic financial risks in China based on three-dimensional structural analysis" (NO.

19YJA790098), Youth Science and Technology Innovation Fund For Basic Scientific Research Operating Expenses of NUAA "Research on the growth strategy of domestic P2P online lending platform based on dynamic model" (NO. NR2017003)

DOI: 10.46609/IJSSER.2020.v05i01.004 URL: https://doi.org/10.46609/IJSSER.2020.v05i01.004
\end{abstract}

\section{ABSTRACT}

In recent years, there have been frequent failures and bankruptcies of $\mathrm{P} 2 \mathrm{P}$ platforms in China, among which private platforms have become a high-explosive area, and a large number of investors suffer from high risks and high losses due to their choice of private P2P investment with high returns. Since 2019, supervision has been increased, classified disposal and benign withdrawal will become the future development trend. Therefore, how to carry out risk assessment and conduct classified and targeted disposal by regulators has become an urgent problem. In view of this, this paper takes 123 private platform as research object. After constructing the risk assessment indicator system, the AHP-entropy weight and grey relational method are applied and found that the platforms with low registered capital, high concentration of borrowing and fund outflows for a long time have a higher risk. Therefore, when conducting risk assessment and disposal of the platform, the regulator should properly remove such platforms, so as to provide decision reference for the regulator's platform disposal.

Keywords: Private Sector Platform, Grey Relational Method, Risk Assessment, Internet Finance

\section{INTRODUCTION}

P2P online lending platform is positioned at the long tail customer group, which has brought huge impact on traditional finance with its characteristics of low transaction cost, high turnover efficiency and a variety of investment and financing channels. In China, According to the 
different founders, the P2P platform mainly includes five sectors: banking sector, state-owned sector, venture capital sector, listed sector and private sector. Private P2P platforms are set up by private enterprises or private capital. As they have the earliest start and low threshold, they account for the highest proportion among all types of platforms. At the beginning of 2014, the transaction volume of the private sector in China accounted for as high as $85 \%$ (Figure 1). Since 2014, the state began to introduce various policies to strictly manage the platform. Many risks behind the high returns of the private sector platform also began to accumulate and be exposed. As of December 2018, the transaction amount accounts for about $30 \%$ and tends to be stable. By comparing the number of new problem platforms in each sector in each month since 2014, it is found that the number of private sector always accounts for a large proportion of the total number of new platforms, accounting for no less than $75 \%$ (Figure 2).

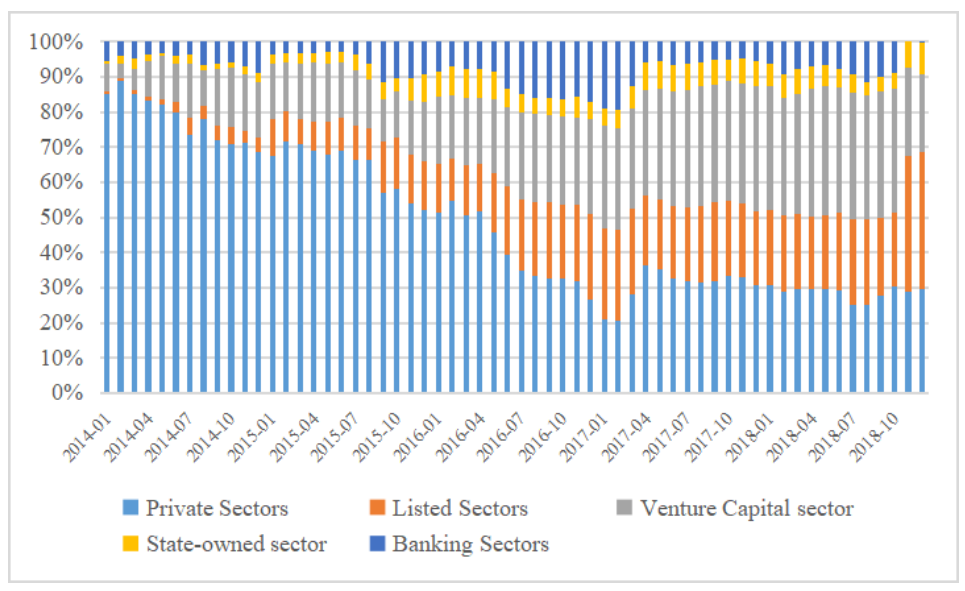

Figure 1: Comparison of Trading Volume of Platforms of Different Sectors

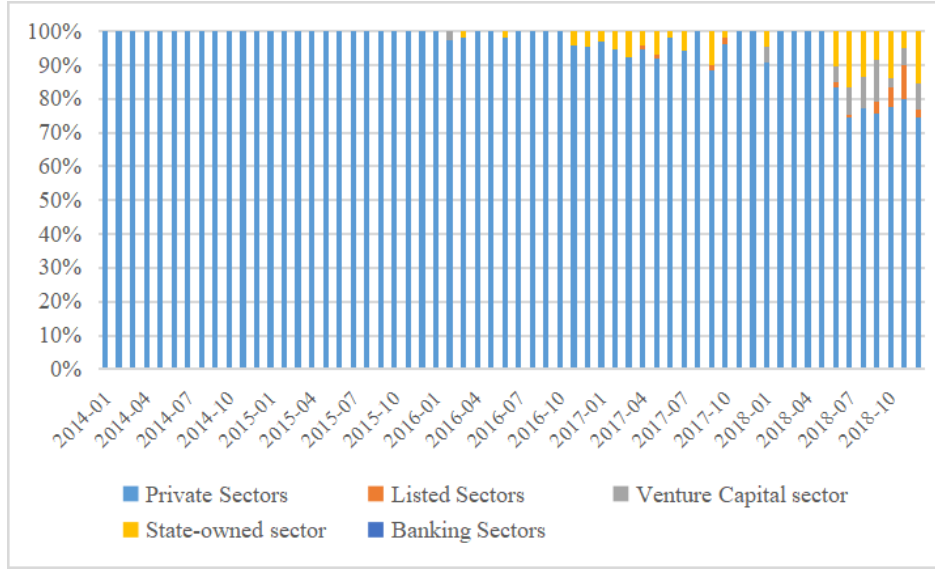

Figure 2: Comparison of The Number of New Problem Platforms Added of Different Sectors 


\section{International Journal of Social Science and Economic Research}

ISSN: $2455-8834$

Volume: 05, Issue: 01 "January 2020"

In response to the frequent explosion of the disorder, the regulatory policy is also frequent. In August 2016, the interim measures for the management of business activities of online lending information intermediaries were released, and the first formal measures for the management of P2P online lending industry were introduced. In 2017, relevant guidelines on the filing system, fund depository and information disclosure were issued, forming a "1+3" initial regulatory framework with the interim measures. In November 2018, P2P online lending officially came under the jurisdiction of the China banking regulatory commission (CBRC). From the second half of 2019, regulation further accelerate. On November 12, li junfeng, director of the inclusive finance department of the CBRC, said that the special regulation of Internet finance is "mainly based on withdrawal", with classified disposal to strengthen the regulation on the future direction of P2P. However, at the same time, the treatment of P2P platforms should not be a one-size-fitsall approach. For institutions with no serious violations of laws and regulations, good financial technology foundation and certain strength of shareholders, they can be transformed into small loan companies. Institutions with strong capital strength that meet regulatory requirements can be restructured into consumer finance companies or other licensed financial institutions. Therefore, for regulators, how to evaluate the risks of existing P2P platforms and classify them has become an urgent problem. On one hand, the risk assessment of the existing private sector is conducive to the effective resolution of stock risks by the regulatory layer and the targeted disposal of different platforms. On the other hand, after classified disposal, the newly transformed small loan companies or other licensees can take this risk assessment as a reference to pay close attention to potential risk points and reduce the generation of new risks.

Most of the research on risk assessment of $\mathrm{P} 2 \mathrm{P}$ platform by Chinese and foreign scholars is based on the causes of platform risk and the perspective of government supervision. For the risks and causes of P2P platforms, many scholars believe that the risks of P2P platforms are difficult to control, and the main reason is the information asymmetry. Information asymmetry enables financiers to conceal information that is not favorable to them, leading to a great increase in the risk of default. In addition, information asymmetry will also bring technical risks, and lead to the lack of supervision, easy to produce illegal fund-raising and other problem ${ }^{[1-4]}$ (Arrow,1994;Jin G.Z,2008;Lin M,2013;Luo Sidan,2014). Helfat (2007) ${ }^{[5]}$ believes that the internal drivers of the platform and the external economic environment are also important factors to measure the risk of the platform. On this basis, Angilella (2015) ${ }^{[6]}$ proposed that credit risk should also be included in the criteria for platform risk consideration. Daniel (2019) ${ }^{[7]}$ et al. conducted further research on credit risk and found that $\mathrm{P} 2 \mathrm{P}$ platforms not only reduced credit cost and improved service efficiency, but also made it difficult to accurately measure credit risk, which would endanger the stability of the entire financial system. Eunkyoung Lee (2012) ${ }^{[8]}$ et al. studied the P2P market in South Korea and found that irrational investment of investors and unsecured loans of borrowers were the main causes of risks. Ye qing et al. (2016) ${ }^{[9]}$ used the Probit model to find that in 


\section{International Journal of Social Science and Economic Research}

ISSN: $2455-8834$

Volume: 05, Issue: 01 "January 2020"

addition to interest rate being an important variable for identifying the problematic platform, weak strength, single target type and lack of risk control ability are also risks faced by the platform in China. Wu yunke (2017) ${ }^{[10]}$ et al. believed that the liquidity risk faced by the problem platform was mainly caused by the mismatch between the amount and time of liabilities and assets. When scholars study the risks of P2P platforms, they mainly study them based on the relationship between investors and borrowers. Barasinska (2009) ${ }^{[11]}$ argued from the perspective of investors that women perform less rationally than men, pursue higher interests, and eventually invest in borrowers with poor credit. Craig r. Everett $(2015)^{[12]}$ believes that in P2P online loans, if there is a certain social relationship between the lender and the borrower, the probability of default will change from high to low with the distance of the relationship.

Based on the many risks of $\mathrm{P} 2 \mathrm{P}$ online lending platforms, scholars have also carried out corresponding studies on industry regulation. Congressional Committees (2011) ${ }^{[13]}$ proposed that corresponding supervision must be implemented as soon as possible along with the development of Internet finance, and regulatory responsibilities need to be timely defined and coordinated. Most of the Chinese scholars also believe that regulator should build a multi-level regulatory system. Yu Lin et al. (2015) ${ }^{[14]}$ proposed regulatory measures from the perspective of regulators by establishing a game model including enterprises, borrowers, lenders and regulators. Fang xing $(2018)^{[15]}$ found that the establishment of industry associations can promote the exposure of problem platforms, and the promotion of industry regulation and self-discipline is also conducive to restore the confidence of market investors. Pan jing $(2018)^{[16]}$, referring to the regulation rules of Internet finance in the United States and the United Kingdom, believes that relevant rules of Internet finance in China should be improved from the aspects of establishing classified access rules and adding rules of exemption for small amounts.

Although there have been preliminary studies on the causes of risk and evaluation of P2P platforms, most of the studies, especially those of foreign scholars, are based on the perspective of platform borrowers and regulators, which is related to the development of $\mathrm{P} 2 \mathrm{P}$ in foreign countries. $\mathrm{P} 2 \mathrm{P}$ is more mature in foreign countries, and the supporting regulatory system is effective. However, the development of P2P platforms in China is not yet mature, and the barbaric growth of low threshold makes P2P platforms mixed, and many platforms are called information intermediaries, which are actually credit intermediaries. Therefore, the development environment and characteristics of $\mathrm{P} 2 \mathrm{P}$ platforms in China are different from those of foreign countries. At present, the supervision of $\mathrm{P} 2 \mathrm{P}$ platforms in China is becoming increasingly strict. Since the second half of 2019, Hunan and Chongqing and other provinces have begun to take actions to clean up online loans and remove platforms that fail to meet regulatory requirements. In this context, for regulators, how to effectively deal with platforms in different categories, not only to clear platforms that fail to meet regulatory requirements, but also to give platforms that 


\section{International Journal of Social Science and Economic Research}

ISSN: $2455-8834$

Volume: 05, Issue: 01 "January 2020"

meet regulatory requirements and have strong capital strength new vitality, has become an important issue. In addition, most existing studies study the platform as a whole, but the private sector with the most potential risks in the recent thunderstorm has its own characteristics and risk level different from other sectors, but the targeted studies on it are still insufficient. In order to make up for the above shortcomings, based on the current background of strong supervision and classified disposal of $\mathrm{P} 2 \mathrm{P}$ platforms, this paper carries out risk assessment research on existing private platforms, with a view to providing effective classified disposal for regulators and specific management suggestions for platforms with different risk levels.

\section{CONSTRUCTION OF ASSESSMENT INDICATOR SYSTEM}

\subsection{Indicator System Review}

\section{(1) Indicator system of existing research}

In November 2018, the P2P online lending industry was formally incorporated into the jurisdiction of the CBRC. Therefore, when selecting indicators, scholars mostly refer to the bank risk regulatory standards to build risk assessment indicators for $\mathrm{P} 2 \mathrm{P}$ platforms. Zhiyuan Jiang et al.(2019) ${ }^{[17]}$ grasped from the aspects of liquidity, security and profitability .Wang Liyong et al.(2016) ${ }^{[18]}$ referred to the Basel III and combined with China's supervision of bank risks, indicators from liquidity risk to market risk and credit risk are used. Guo Haifeng et al.(2015) ${ }^{\text {[19] }}$ believe that profitability, market size, security, and growth are important factors for evaluating online loan platforms.

Summarize the indicators selected by the predecessors, it is found that from the perspective of liquidity, it mainly includes the fund flow of the platform and the situation of investors. From the perspective of security, it mainly includes the use of the platform's funds and compliance with the platform. From the perspective of profitability, it mainly includes the various financial indicators of the platform, as well as the platform's image and transaction volume.

\section{(2) Indicator system of third-party institution}

As private $\mathrm{P} 2 \mathrm{P}$ platforms have different characteristics from banks, the risks they face are also different from those of banks. Therefore, it is necessary to take into account the characteristics of private $\mathrm{P} 2 \mathrm{P}$ platforms more specifically. As the first and largest third-party online loan information platform in China, wangdaizhijia (https://www.wdzj.com) provides data for the research of $\mathrm{P} 2 \mathrm{P}$ platforms. Therefore, after studying the indicators of previous studies, this paper further refers to the indicators of private $\mathrm{P} 2 \mathrm{P}$ platforms of wangdaizhijia. 
After rating and scoring the platform from various dimensions, wangdaizhijia obtains the "development index", that is, the overall rating. The development index has six dimensions: transaction points, popularity points, compliance points, brand, dispersion and transparency. Among them, transaction points reflect the trading volume of the platform, popularity points reflect the number of investors and borrowers of the platform, compliance points reflect the compliance of the platform, brand reflects the popularity of the platform, dispersion reflect the degree of dispersion of borrowers, and transparency reflects the degree of information disclosure of the platform.

\subsection{Construction of Indicator System}

A comparative study on the rating index of wangdaizhijia and the indicator system summarized by existing researches shows that the two have a high coincidence degree in the assessment dimension. Therefore, it is reasonable and scientific to construct the indicator system based on the comparison and refinement of the two systems. Specifically, the two are similar in five dimensions: platform strength, investor profile, trading volume profile, capital security profile and compliance profile. Next, the indicators are detailed to build the assessment indicator system.

\section{Table 1: Comparison of existing research and third-party institution assessment indicators}

\begin{tabular}{ccccc}
\hline & Existing research & $\begin{array}{c}\text { Third-party } \\
\text { institution }\end{array}$ & Explanation & Dimension \\
\hline Platform image & Brand & Reflect platform strength & Platform strength \\
Same & Investor situation & Popularity Points & $\begin{array}{c}\text { Reflect the situation of } \\
\text { platform investors }\end{array}$ & Growth ability \\
& Volume situation & Transaction points & Reflect the transaction & \\
& Use of funds & Dispersion & Reflecting operations & Operating risk \\
& Compliance & $\begin{array}{c}\text { Compliance } \\
\text { points }\end{array}$ & Reflect compliance & Compliance risk \\
& Flow of funds & Reflect fund flow & Liquidity risk
\end{tabular}

Different indicator

Financial situation

Transparency 


\section{International Journal of Social Science and Economic Research}

ISSN: $2455-8834$

Volume: 05, Issue: 01 "January 2020"

Comparing the two different indicators, since the research object of this paper is private $\mathrm{P} 2 \mathrm{P}$ platforms that are not listed, the financial situation of most platforms is not available, so this paper does not include financial indicator. The platforms selected in this paper are all platforms with relatively complete public data, so the transparency of research objects in this paper is the same, so transparency is not included. In summary, the assessment indicators determined in this paper include platform strength, investor situation, trading volume, capital use, compliance, and capital flow.

Based on previous studies and the characteristics of $\mathrm{P} 2 \mathrm{P}$ platform, this paper constructs an assessment system with 5 dimensions and 8 indicators. Considering the size of the differences between different platforms, relevant indicators are selected as much as possible. At the same time, combined with the availability of data, this paper comprehensively considers the platform strength, growth ability, operational risk, compliance risk and liquidity risk of the platform, and establishes the P2P risk assessment indicator system of China's private system. The following is a detailed introduction of each indicator.

(1) Platform strength indicators: operating time and registered capital. The length of operation time reflects the operational capacity of the platform. Usually, the shorter the operation time, the less stable the development of the platform, and the weaker the resistance to risk. Registered capital is the capital guarantee of the platform and the support for the safe and smooth development of the platform's various businesses, reflecting the platform's financial strength. The lower the capital, the worse the ability to resist risk.

(2) Growth ability indicators: deviation degree of transaction volume growth rate and deviation degree of investor growth rate. In order to reflect the development trend of the platform and the availability of data, the geometric average growth rate in the fourth quarter of 2018 is selected. The growth rates of transaction volume and investors reflect the growth ability and competition level of the platform. When measuring the growth capacity of the platform, there are potential risks of too high or too low the growth rate. Too high implies the hidden worries of barbaric growth, too low implies the risk of being eliminated by the industry. Therefore, when defining the direction of indicators, we need to deal with the indicators relatively. The average growth rate of the industry is regarded as sustainable growth rate, which is the growth rate of stable development of the platform. Therefore, the deviation between the actual growth rate and the sustainable growth rate of the platforms is calculated as the indicator. The larger the deviation, the greater the risk.

(3) Operating risk indicators: proportion of top ten borrowers to repay and the risk-return ratio. The proportion of the top ten borrowers to repay reflects the overall loan concentration of the platform. If the top ten borrowers have a high proportion to repay, once someone defaults and 


\section{International Journal of Social Science and Economic Research}

ISSN: $2455-8834$

Volume: 05, Issue: 01 "January 2020"

fails to repay, the capital chain will break, which will have a significant impact on the financial security of the platform. Risk-return ratio (platform leverage/return) considers the benefits and risks of the platform. It overcomes the one-sidedness of measuring the benefits and risks solely by the rate of return or the level of leverage, in which the leverage is obtained by the ratio of the platform's outstanding debt and registered capital. The greater the ratio, the greater the platform risk.

(4) Compliance risk indicator: whether bank deposit. In August 2018, the State Mutual Fund Regulation Office issued the Notice on Compliance Inspection of P2P Internet Lending Institutions, requiring Internet Lending Institutions to strictly check whether the platform is strictly defined as an information intermediary, whether there is a fund pool, etc. If there is no bank deposit for the platform funds, the transaction of funds cannot be guaranteed to be separated from the management, and the platform may make use of the funds for illegal operation, which increases the risk of illegal operation of the platform. As the regulation is tightened, platforms without bank deposits are required to rectify compliance, and those still without bank deposits may be eliminated from the market. When quantifying this index, 0-1 valuation method is selected, 0 means without bank deposit, 1 means with bank deposit 。

(5) Liquidity risk indicator: ratio of net monthly capital inflow to transaction volume. If the fund is in the net outflow state for a long time, the amount of repayment is large and the amount of borrowing is small, the platform may face the pressure of payment. To reflect the liquidity situation of the platform over a period of time, the monthly net capital inflow in the fourth quarter of 2018 was selected to reflect the fund flow situation of the platform over a period of time. At the same time, considering the size of the platform, set the relativity indicator. Therefore, the ratio of monthly average net capital inflow and transaction volume in the fourth quarter of 2018 is selected to reflect liquidity risk. If the ratio is too low or even negative, it indicates that the platform has potential liquidity risk.

Table 2: Risk Assessment Indicator System of Private Platform

\begin{tabular}{|c|c|c|}
\hline Dimension & Indicator & Code \\
\hline \multirow{2}{*}{ Platform strength } & Operating time(month) & $\mathrm{X} 1$ \\
\hline & Registered capital(million) & $\mathrm{X} 2$ \\
\hline \multirow{2}{*}{ Growth ability } & Deviation degree of transaction volume growth rate $(\%)$ & $\mathrm{X} 3$ \\
\hline & Deviation degree of investor growth rate $(\%)$ & $\mathrm{X} 4$ \\
\hline Operational risk & Proportion of top ten borrowers to repay( $\%)$ & X5 \\
\hline www.ijsser.org & Copyright (C IJSSER 2020, All rights reserved & Page 55 \\
\hline
\end{tabular}


International Journal of Social Science and Economic Research

ISSN: 2455-8834

Volume: 05, Issue: 01 "January 2020"
Risk-return ratio
X6
Compliance risk
whether bank deposit $(1=\mathrm{Y}, \quad 0=\mathrm{N})$
$\mathrm{X} 7$
Liquidity risk
Ratio of net monthly capital inflow to transaction volume
$\mathrm{X} 8$

\section{ALGORITHM STEPS}

\subsection{Weight Calculation}

There are two main ways of weight calculation, subjective weighting method and objective weighting method. The subjective weighting method is combined with expert opinions to weight various indicators, and the weight obtained has certain convincing force. But because the weight is given artificially, there is inevitably subjective interference. The objective weighting method determines the indicator weight according to the size of the indicator variability. The greater the difference is, the greater the weight will be. It avoids the human interference of subjective weighting but may lack economic significance. Therefore, both subjective and objective weighting methods have corresponding disadvantages when they are of certain significance. To overcome this point, this paper selects the combination of subjective and objective weighting method, the subjective weighting method selects the Analytic Hierarchy Process(AHP), the objective weighting method selects the entropy weight method, calculates the two groups of weights, and obtains the comprehensive weight by re-weighting.

(1) Weights under AHP

Through expert interviews, the judgment matrix $\mathrm{U}=\left(\mathrm{u}_{\mathrm{ij}}\right)_{8 * 8}, \mathrm{~V}=\left(\mathrm{v}_{\mathrm{ij}}\right)_{2 * 2}$ was constructed. Taking the first-order indicator layer as an example, the judgment matrix $\mathrm{U}$ is:

Table 3: Judgment Matrix of First-order Indicator Layer

\begin{tabular}{cccccc}
\hline & $\begin{array}{c}\text { Platform } \\
\text { strength }\end{array}$ & Growth ability & $\begin{array}{c}\text { Operational } \\
\text { risk }\end{array}$ & $\begin{array}{c}\text { Compliance } \\
\text { risk }\end{array}$ & Liquidity risk \\
\hline Platform strength & 1 & 4 & 3 & 4 & 4 \\
Growth ability & $1 / 4$ & 1 & $1 / 3$ & 2 & 1 \\
Operational risk & $1 / 3$ & 3 & 1 & 4 & 2 \\
Compliance risk & $1 / 4$ & $1 / 2$ & $1 / 4$ & 1 & $1 / 2$
\end{tabular}


International Journal of Social Science and Economic Research

ISSN: 2455-8834

Volume: 05, Issue: 01 "January 2020"

$\begin{array}{llllll}\text { Liquidity risk } & 1 / 4 & 1 & 1 / 2 & 2 & 1\end{array}$

The indicator weight was calculated by MATLAB and the consistency test was carried out. $\mathrm{CI}=0.034<1$. The consistency test was passed, so the first-level index weight was determined as shown in Table 4.

Table 4: Weight of First-order Indicator Layer under AHP

\begin{tabular}{lccccc}
\hline & Platform strength & Growth ability & Operational risk & Compliance risk & Liquidity risk \\
\hline Weight & 0.462 & 0.110 & 0.241 & 0.070 & 0.117 \\
\hline
\end{tabular}

Then, the second-level indicators were weighted. After the first and second index weights are obtained, the indicator weights under the AHP are finally obtained.

Table 5: Weights under AHP

\begin{tabular}{lcccccccc}
\hline & X1 & X2 & X3 & X4 & X5 & X6 & X7 & X8 \\
\hline Weight & 0.077 & 0.385 & 0.073 & 0.037 & 0.201 & 0.040 & 0.070 & 0.117 \\
\hline
\end{tabular}

(2) Weights under entropy weight method

According to 123 objects and 8 indicators, the matrix $X=(x i j) 123 * 8$ is formed, and the standardized matrix is obtained by standardization, which is recorded as Y123*8. When standardizing, there are different ways to deal with the positive and negative indicators, for deviation degree of transaction volume growth rate (X3), deviation degree of investor growth rate $(\mathrm{X} 4)$, proportion of top ten borrowers to repay (X5), risk-return ratio (X6) as positive indicators,

$$
Y_{i j}=\frac{X_{i j}-\min \left(x_{j}\right)}{\max \left(x_{j}\right)-\min \left(x_{j}\right)}
$$

For operating time (X1), registered capital (X2), whether bank deposit (X7) and ratio of net monthly capital inflow to transaction volume (X8) as reverse indicators,

$$
Y_{i j}=\frac{\max \left(x_{j}\right)-X_{i j}}{\max \left(x_{j}\right)-\min \left(x_{j}\right)}
$$


After standardization, the entropy value of indicator $J$ is recorded as $E_{j}$.

$$
E_{j}=-\ln (123)^{-1} * \sum_{i=1}^{123} p_{i j} \ln p_{i j}
$$

where,

$$
p_{i j}=\frac{Y_{i j}}{\sum_{i=1}^{123} Y_{i j}}
$$

If $\mathrm{p}_{\mathrm{ij}}=0$, define $\lim _{p_{i j} \rightarrow 0} p_{i j} \ln p_{i j}=0$

The weight of indicator $\mathrm{j}$ is calculated according to the entropy value.

$$
\omega_{j}=\frac{1-E_{j}}{8-\sum_{j=1}^{8} E_{j}}
$$

Finally, the indicator weights under entropy weight method are finally obtained.

Table 6: Weights under Entropy Weight Method

\begin{tabular}{ccccccccc}
\hline & $\mathrm{X} 1$ & $\mathrm{X} 2$ & $\mathrm{X} 3$ & $\mathrm{X} 4$ & $\mathrm{X} 5$ & $\mathrm{X} 6$ & $\mathrm{X} 7$ & $\mathrm{X} 8$ \\
\hline Weight & 0.004 & 0.002 & 0.095 & 0.120 & 0.168 & 0.293 & 0.317 & 0.002 \\
\hline
\end{tabular}

(3) Combined weights

Considering that private $\mathrm{P} 2 \mathrm{P}$ platforms play an important role in the development of China's $\mathrm{P} 2 \mathrm{P}$ online loan industry, and the ultimate purpose of this paper is to provide reference for regulators to make decisions on classification and disposal, the weight obtained by AHP is slightly emphasized in the comprehensive weighting. Therefore, the weight obtained by AHP is 0.6, and the weight obtained by entropy weight method is 0.4 , as shown in the formula:

$$
\omega=\alpha \cdot \omega_{1}+(1-\alpha) \cdot \omega_{2}, \quad \alpha=0.6
$$

\subsection{Relevance Degree Calculation}


International Journal of Social Science and Economic Research

ISSN: $2455-8834$

Volume: 05, Issue: 01 "January 2020"

The economic system is a typical grey system, and the theory of grey system has been widely used in the economic system since its birth. Recently, with the increasing popularity of P2P online loan industry, research focus on the risks of online loan industry. Considering that the development of $\mathrm{P} 2 \mathrm{P}$ online loan industry in China is not sound and relevant data and information are scarce, some data are clearly disclosed, but there are still a lot of data gray uncertainty, so the grey relational method is used to study some known public information, which is applicable to the analysis of P2P platforms, and the calculation method is as follows.

First, data standardization. In order to ensure the consistency of the dimensions of the data, the mean image of each sequence is calculated and recorded as $\mathrm{X}$ '.

$$
X_{i j}^{\prime}=\frac{X_{i j}}{\overline{X_{i}}}
$$

Second, determine the reference sequence $C=(\mathrm{c} 1, \mathrm{c} 2 \ldots \mathrm{cn})$. Since the purpose of this paper is to evaluate the risk of $\mathrm{P} 2 \mathrm{P}$ platforms, the reference sequence selected in this paper is the platform with the highest risk, which is composed of the worst value of each indicator and represents a virtual reference sequence, namely the platform with the highest risk. When determining the reference sequence of this paper, the minimum value in each sequence is selected as the reference value for four adverse indicators, namely, operating time, registered capital, whether bank deposit and liquidity ratio. The maximum value in each sequence is selected as the reference value for four positive indicators, namely, the deviation degree of transaction volume growth rate, the deviation degree of investor growth rate, the proportion of the top ten borrowers to repay, and the risk-return ratio.The idea of analysis is that if the relevance between comparison sequence and reference sequence is relatively high, it shows that the indicators of the platform are close to the reference level in the industry, and the platform risk is relatively high. On the contrary, it shows that the indicators of the platform are quite different from the reference sequence, and the risk level of the platform is also low.

Third, calculate the relevance coefficient $\gamma$ ij of each subject. $\xi$ is the resolution coefficient, usually 0.5 .

$$
\gamma_{i j}=\frac{\min _{i} \min _{i}\left|X_{i j}^{\prime}-c_{j}\right|+\xi \max _{i} \max _{i}\left|X_{i j}^{\prime}-c_{j}\right|}{\left|X_{i j}^{\prime}-c_{j}\right|+\xi \max _{i} \max _{i}\left|X_{i j}^{\prime}-c_{j}\right|}
$$

Fourth, calculate the relevance degree $\gamma \mathrm{ij}$. $\omega \mathrm{j}$ is the weight obtained by using the method of comprehensive weighting. 


$$
\gamma_{i}=\sum_{i=1}^{m} \omega_{j} \gamma_{i j}, j=1,2, \ldots n
$$

\section{EMPIRICAL ANALYSIS}

\subsection{Weight Analysis}

First, the weight of each indicator is calculated according to formula (6), as shown in Table7.

Table 7: Weight of Each Indicator

\begin{tabular}{ccccccccc}
\hline & $\mathrm{X} 1$ & $\mathrm{X} 2$ & $\mathrm{X} 3$ & $\mathrm{X} 4$ & $\mathrm{X} 5$ & $\mathrm{X} 6$ & $\mathrm{X} 7$ & $\mathrm{X} 8$ \\
\hline$\omega_{1}$ & 0.077 & 0.385 & 0.073 & 0.037 & 0.201 & 0.040 & 0.070 & 0.117 \\
$\omega_{2}$ & 0.004 & 0.002 & 0.095 & 0.120 & 0.168 & 0.293 & 0.317 & 0.002 \\
$\omega$ & 0.048 & 0.232 & 0.082 & 0.070 & 0.188 & 0.141 & 0.169 & 0.071 \\
\hline
\end{tabular}

According to the comprehensive weight results, X2, X5 and X7 have the largest weight. First of all, the registered capital (X2) represents the capital strength of the platform and also reflects the ability to cope with risks. Strong financial support, on the one hand, guarantees the platform's qualification and makes the platform more formal. On the other hand, sufficient capital enables the platform to be able to carry out various businesses, with stable anti-risk capability, and to use appropriate leverage to increase the level of earnings. Therefore, registered capital is crucial to measure platform risk. Second, proportion of top ten borrowers to repay (X5) reflects the concentration of borrowing money, if the platform borrowing is too concentrated in the hands of a small number of borrowers, once some of the borrower defaulted, due to its default funds account for larger proportion, makes a large number of investors cannot get their money back, easy to produce runs, endanger the normal operation of platform. In addition, whether bank deposit (X7) reflects the security of funds, the supervision and management of the use of platform funds is conducive to the safe and reasonable flow of funds, and can effectively reduce the behavior of capital flow in the grey zone. In terms of supervision, regulators are increasingly strict about whether the platform has bank deposit and whether there is capital pool. In particular, after the formation of the "1+3" regulatory system, requirements for bank deposit are more stringent, so whether there is bank deposit also affects the platform risks to a large extent.

\subsection{Relevance Degree Analysis}


International Journal of Social Science and Economic Research

ISSN: 2455-8834

Volume: 05, Issue: 01 "January 2020"

According to the relevance coefficient and comprehensive weight obtained, the relevance degree of each platform was calculated, and the descending order was shown in Table 8.

Table 8: Ranking of Platform Relevance Degree

\begin{tabular}{|c|c|c|c|c|c|c|c|c|}
\hline Ranking & Platform & $\mathrm{RD}$ & Ranking & platform & $\mathrm{RD}$ & Ranking & platform & $\mathrm{RD}$ \\
\hline 1 & Bingchuancaifu & 0.898 & 42 & Fangyuanjinfu & 0.800 & 83 & Yueshangdai & 0.757 \\
\hline 2 & $\begin{array}{c}\text { Lianhaochuang } \\
\text { tou }\end{array}$ & 0.896 & 43 & Jidaizhijia & 0.800 & 84 & Jinxinwang & 0.757 \\
\hline 3 & Mutouren & 0.889 & 44 & Yunqiandai & 0.798 & 85 & 168jinfu & 0.757 \\
\hline 4 & Duoweidu & 0.888 & 45 & Hongdingjinrong & 0.798 & 86 & Jianyidai & 0.757 \\
\hline 5 & Huienziben & 0.881 & 46 & Cheyidai & 0.798 & 87 & Huaxiajinrong & 0.756 \\
\hline 6 & 58hongli & 0.865 & 47 & Xiaofujinrong & 0.797 & 88 & Xinhedajinrong & 0.755 \\
\hline 7 & 58caifu & 0.856 & 48 & Zhongxingcaifu & 0.793 & 89 & Jinyuanbaolicai & 0.752 \\
\hline 8 & Lianlianjinrong & 0.855 & 49 & Mizujinrong & 0.791 & 90 & Tangguojinrong & 0.752 \\
\hline 9 & $\begin{array}{c}\text { Daokoujinrong } \\
\text { wang }\end{array}$ & 0.852 & 50 & Dibiaojinrong & 0.790 & 91 & $\begin{array}{c}\text { Gongchangweiji } \\
n\end{array}$ & 0.751 \\
\hline 10 & $\begin{array}{c}\text { Nongxinshangd } \\
\text { ai }\end{array}$ & 0.851 & 51 & Anxintou & 0.790 & 92 & Edushiqianbao & 0.750 \\
\hline 11 & Shiliuke & 0.851 & 52 & Wanfubao & 0.788 & 93 & Xinfujinrong & 0.749 \\
\hline 12 & Matouyi & 0.848 & 53 & 178wangdai & 0.787 & 94 & Huiyingjinfu & 0.748 \\
\hline 13 & Jiliwang & 0.847 & 54 & Lanjingjinrong & 0.786 & 95 & Qiedai & 0.748 \\
\hline 14 & Guoyijinfu & 0.843 & 55 & Lizicaifu & 0.784 & 96 & Qianhezi & 0.747 \\
\hline 15 & $\begin{array}{c}\text { Xiangrongwan } \\
\mathrm{g}\end{array}$ & 0.843 & 56 & Letouchuangfu & 0.782 & 97 & Xiaogelicai & 0.747 \\
\hline 16 & Hongxuejinxin & 0.840 & 57 & Guoerjinrong & 0.781 & 98 & $\begin{array}{c}\text { Zhangzhongcaif } \\
\text { u }\end{array}$ & 0.747 \\
\hline 17 & Aibendijinfu & 0.839 & 58 & Xihuanqian & 0.780 & 99 & Xiaojilicai & 0.746 \\
\hline
\end{tabular}


International Journal of Social Science and Economic Research

ISSN: $2455-8834$

Volume: 05, Issue: 01 "January 2020"

\begin{tabular}{|c|c|c|c|c|c|c|c|c|}
\hline 18 & Caishenzaixian & 0.838 & 59 & Yidianqian & 0.779 & 100 & Qianlindai & 0.745 \\
\hline 19 & Yixiangjinrong & 0.833 & 60 & Hengyirong & 0.778 & 101 & Xiaolianjinrong & 0.744 \\
\hline 20 & Puhuilicai & 0.833 & 61 & Youtoujinfu & 0.778 & 102 & Xinhedai & 0.744 \\
\hline 21 & Sifangtou & 0.831 & 62 & Xinrongtouzi & 0.777 & 103 & Xiaoniuzaixian & 0.743 \\
\hline 22 & Hurongbao & 0.830 & 63 & Huichengjinfu & 0.777 & 104 & Bangbangtang & 0.741 \\
\hline 23 & $\begin{array}{c}\text { Yidiantongcaif } \\
\mathrm{u}\end{array}$ & 0.830 & 64 & $\begin{array}{c}\text { Xiaoshushidaiwa } \\
\text { ngdai }\end{array}$ & 0.777 & 105 & Lujinsuo & 0.739 \\
\hline 24 & Rongxinwang & 0.827 & 65 & Checaiwang & 0.776 & 106 & Zhifudai & 0.739 \\
\hline 25 & Xiaopingdai & 0.826 & 66 & Weiweidai & 0.776 & 107 & Zhongrongbao & 0.739 \\
\hline 26 & Yumaojinfu & 0.825 & 67 & Qianpenwang & 0.775 & 108 & Yangqianguan & 0.734 \\
\hline 27 & Gaigeniu & 0.823 & 68 & $\begin{array}{l}\text { Honglingchuangt } \\
\text { ou }\end{array}$ & 0.774 & 109 & Duolajucai & 0.733 \\
\hline 28 & Youxicaifu & 0.822 & 69 & Weiyangpuhui & 0.773 & 110 & Duoyingpuhui & 0.732 \\
\hline 29 & Yongbeijinrong & 0.820 & 70 & Xiaonuolicai & 0.771 & 111 & Jinrojiecai & 0.732 \\
\hline 30 & $\begin{array}{c}\text { Aotuaojinfuwa } \\
\text { ng }\end{array}$ & 0.820 & 71 & Ruidajinfu & 0.771 & 112 & Tongqianguan & 0.732 \\
\hline 31 & Yonghejinrong & 0.816 & 72 & Changjidai & 0.769 & 113 & Zhihsangjinrong & 0.731 \\
\hline 32 & Haotianjinrong & 0.815 & 73 & Qianba & 0.768 & 114 & Yinguzaixian & 0.730 \\
\hline 33 & Enkeedai & 0.814 & 74 & Zhongjinsuo & 0.768 & 115 & Manaowan & 0.727 \\
\hline 34 & $\begin{array}{c}\text { Guanghezhong } \\
\text { zi }\end{array}$ & 0.814 & 75 & Puhuijia & 0.767 & 116 & Juchejinrong & 0.727 \\
\hline 35 & Fudaiwang & 0.811 & 76 & Qichengjinrong & 0.764 & 117 & Xinshengdai & 0.725 \\
\hline 36 & Qianlaiye & 0.810 & 77 & Chengtiezairong & 0.764 & 118 & $\begin{array}{c}\text { Yangcongxiansh } \\
\text { eng }\end{array}$ & 0.725 \\
\hline 37 & Zhongfangbao & 0.809 & 78 & Jilicaifu & 0.763 & 119 & Zhongjinzaixian & 0.725 \\
\hline 38 & Qiandaiwang & 0.805 & 79 & Renrenjucai & 0.762 & 120 & Xiangshangjinfu & 0.723 \\
\hline
\end{tabular}


International Journal of Social Science and Economic Research

ISSN: $2455-8834$

Volume: 05, Issue: 01 "January 2020"

$\begin{array}{ccccccccc}39 & \text { Niwojinrong } & 0.804 & 80 & \text { Yixindai } & 0.760 & 121 & \text { Rongziyi } & 0.723 \\ 40 & \text { Woyaotou } & 0.803 & 81 & \text { Laocaibao } & 0.759 & 122 & \text { Kuaikuaidai } & 0.709 \\ & & & & & & & & \\ 41 & \begin{array}{c}\text { Xinfuchuangto } \\ \mathrm{u}\end{array} & 0.802 & 82 & \text { Suchengjinrong } & 0.757 & 123 & \text { Qingyidai } & 0.704\end{array}$

The ranking of correlation degree provides a decision-making reference for the classification and disposal of regulators. The platform with the highest ranking has a greater correlation with the reference sequence, that is, the platform with the highest risk, indicating that the platform is more risky. Therefore, the regulators can focus on it during the disposal. If the regulatory requirements are not met during the supervision period, it can be dismissed. The platforms at the bottom of the list have less correlation with the reference sequence and are relatively safer. The regulators can further track their capital level, compliance, risk control level, etc. when classifying and disposing them, and urge the transformation of the platforms with better qualifications.

In order to further analyze the risk differences and characteristics of the platform, the top $10 \%$ and the bottom $10 \%$ platforms are selected for further study.

Table 9: Top 10\% and Bottom 10\% Platform Indicators With Relevance Degree

\begin{tabular}{|c|c|c|c|c|c|c|c|c|c|}
\hline Ranking & Platform & $\mathrm{X} 1$ & $\mathrm{X} 2$ & $\mathrm{X} 3$ & $\mathrm{X} 4$ & $\mathrm{X} 5$ & $\mathrm{X} 6$ & $\mathrm{X} 7$ & $\mathrm{X} 8$ \\
\hline 1 & $\begin{array}{l}\text { Bingchuan } \\
\text { caifu }\end{array}$ & 43 & 10 & 32.450 & 0.408 & 30.250 & 0.187 & 1 & -0.150 \\
\hline 2 & $\begin{array}{c}\text { Lianhaoch } \\
\text { uangtou }\end{array}$ & 59 & 12 & 31.009 & 6.497 & 37.320 & 0.206 & 0 & -0.001 \\
\hline 3 & Mutouren & 51 & 10 & 72.988 & 48.904 & 14.380 & 0.670 & 1 & 0.004 \\
\hline 4 & Duoweidu & 40 & 10 & 34.971 & 27.426 & 21.610 & 0.520 & 1 & -0.009 \\
\hline 5 & $\begin{array}{c}\text { Huienzibe } \\
n\end{array}$ & 38 & 10 & 55.101 & 42.421 & 5.040 & 0.371 & 0 & 0.021 \\
\hline 6 & 58hongli & 49 & 10 & 46.684 & 17.848 & 8.450 & 1.381 & 1 & 0.008 \\
\hline 7 & 58caifu & 57 & 50 & 71.211 & 60.852 & 39.970 & 0.145 & 1 & 0.003 \\
\hline 8 & $\begin{array}{c}\text { Lianlianji } \\
\text { nrong }\end{array}$ & 24 & 30 & 79.563 & 103.558 & 0.550 & 1.932 & 1 & -0.021 \\
\hline
\end{tabular}


International Journal of Social Science and Economic Research

ISSN: $2455-8834$

Volume: 05, Issue: 01 "January 2020"

\begin{tabular}{|c|c|c|c|c|c|c|c|c|c|}
\hline 9 & $\begin{array}{l}\text { Daokoujin } \\
\text { rongwang }\end{array}$ & 53 & 10 & 38.882 & 6.582 & 4.870 & 1.242 & 0 & 0.018 \\
\hline 10 & $\begin{array}{c}\text { Nongxins } \\
\text { hangdai }\end{array}$ & 44 & 10 & 21.487 & 14.800 & 71.490 & 0.134 & 1 & 0.000 \\
\hline 11 & Shiliuke & 48 & 20 & 8.541 & 4.341 & 28.730 & 0.199 & 0 & 0.019 \\
\hline 12 & Matouyi & 58 & 10 & 19.982 & 15.128 & 87.480 & 0.092 & 0 & -0.052 \\
\hline$\ldots \ldots$ & $\ldots \ldots$ & $\ldots \ldots$ & $\ldots \ldots$ & $\ldots \ldots$ & $\ldots \ldots$ & ...... & $\ldots \ldots$ & $\ldots \ldots$ & $\ldots \ldots$ \\
\hline 112 & $\begin{array}{c}\text { Tongqiang } \\
\text { uan }\end{array}$ & 25 & 120 & 3.640 & 4.198 & 13.670 & 0.129 & 1 & -0.007 \\
\hline 113 & $\begin{array}{c}\text { Zhihsangji } \\
\text { nrong }\end{array}$ & 43 & 100 & 5.860 & 19.335 & 1.380 & 0.417 & 1 & 0.003 \\
\hline 114 & $\begin{array}{c}\text { Yinguzaix } \\
\text { ian }\end{array}$ & 29 & 100 & 1.439 & 4.099 & 0.020 & 9.063 & 1 & 0.007 \\
\hline 115 & $\begin{array}{c}\text { Manaowa } \\
\mathrm{n}\end{array}$ & 37 & 100 & 7.101 & 7.302 & 0.350 & 4.259 & 1 & -0.023 \\
\hline 116 & $\begin{array}{c}\text { Juchejinro } \\
\text { ng }\end{array}$ & 48 & 50 & 1.539 & 0.719 & 1.980 & 0.380 & 1 & -0.021 \\
\hline 117 & $\begin{array}{l}\text { Xinshengd } \\
\text { ai }\end{array}$ & 45 & 50 & 1.488 & 0.020 & 1.710 & 0.844 & 1 & -0.007 \\
\hline 118 & $\begin{array}{l}\text { Yangcong } \\
\text { xiansheng }\end{array}$ & 41 & 106.25 & 6.138 & 2.866 & 7.610 & 0.142 & 1 & -0.013 \\
\hline 119 & $\begin{array}{c}\text { Zhongjinz } \\
\text { aixian }\end{array}$ & 66 & 100 & 4.437 & 0.031 & 6.500 & 0.151 & 1 & -0.013 \\
\hline 120 & $\begin{array}{l}\text { Xiangshan } \\
\text { gjinfu }\end{array}$ & 65 & 100 & 4.047 & 1.771 & 0.250 & 3.528 & 1 & -0.007 \\
\hline 121 & Rongziyi & 51 & 100 & 2.147 & 1.747 & 6.810 & 0.124 & 1 & -0.018 \\
\hline 122 & $\begin{array}{c}\text { Kuaikuaid } \\
\text { ai }\end{array}$ & 55 & 222.22 & 1.398 & 2.539 & 2.090 & 0.078 & 1 & 0.013 \\
\hline 123 & Qingyidai & 50 & 2500 & 0.374 & 0.015 & 0.190 & 0.420 & 1 & -0.007 \\
\hline
\end{tabular}


Note: in order to analyze the development trend of the platform more intuitively, X3 and X4 indicators of the deviation of growth rate are replaced by X3 'and X4' indicators of rate of growth.

(1) In terms of platform strength, most of the private sector platforms operate for 3-5 years, and difference of registered capital is obvious. Most private P2P platforms operate in 3-5 years, that is, from 2014 to 2016, focusing on the booming period of the industry (Figure3). The registered capital of the top $10 \%$ of the platform is only 10 million yuan, while the capital of the bottom $10 \%$ is more than 100 million yuan, with strong strength (Figure4). Regulatory authorities have also recently imposed stricter requirements on the capital of the platform. In March 2019, the CBRC held a meeting, and regulators will issue new documents to put forward stricter regulations on the registered capital of the platform. Platforms with too little registered capital need to increase capital as soon as possible in the future, but there are some difficulties for many small and medium-sized platforms. Therefore, as an important representation of the strength of the platform, registered capital is crucial to measure the overall anti-risk capability of the platform.

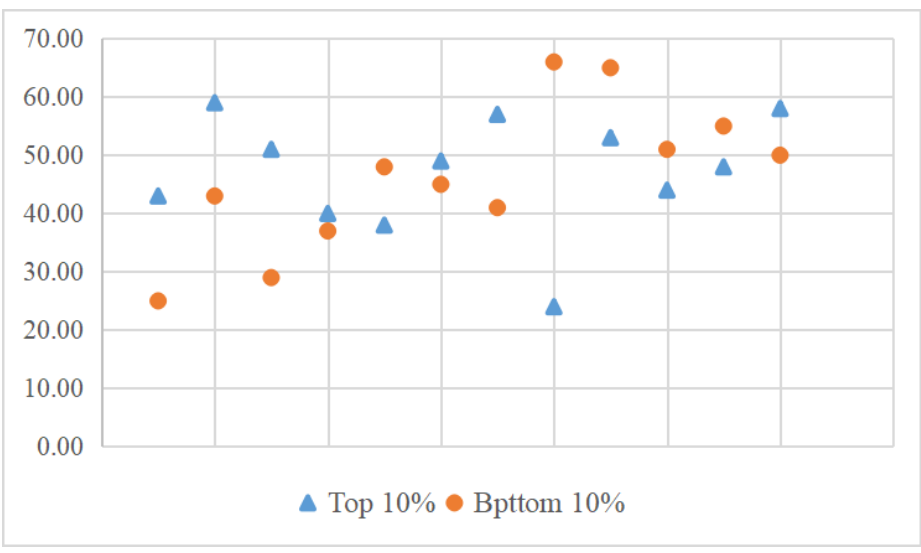

Figure 3: Comparison of Operating Time 
International Journal of Social Science and Economic Research

ISSN: $2455-8834$

Volume: 05, Issue: 01 "January 2020"

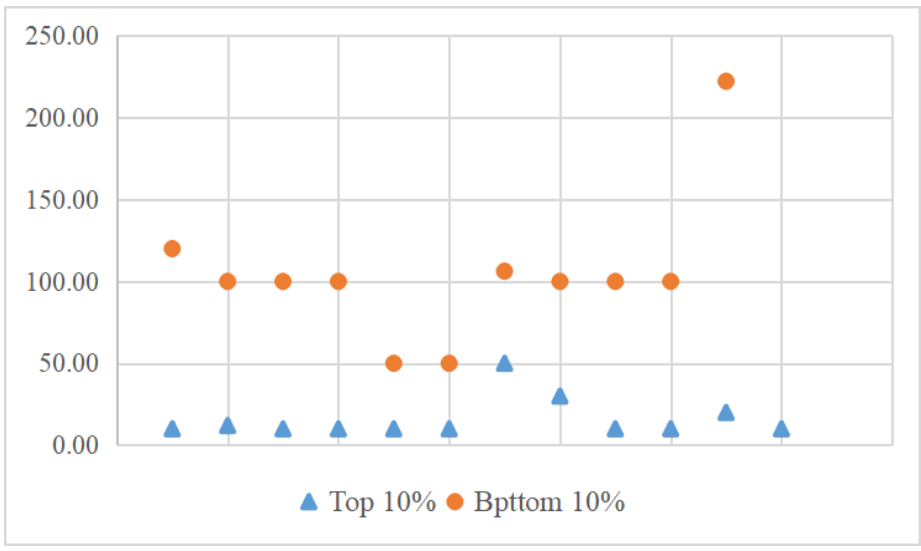

Figure 4: Comparison of Registered Capital

(2) In terms of growth capacity, the growth rate of the top $10 \%$ platform is significantly higher than the industry level, which should arouse vigilance. The growth rate of the top $10 \%$ platform transaction volume and investors is significantly higher than that of the bottom $10 \%$, mostly within the range of $40 \%-80 \%$. After that, the growth rate of the $10 \%$ platform is relatively flat, mostly in the range of $-5 \%$ to $10 \%$, entering the adjustment stage (Figure5-6). From the perspective of the overall situation of the industry, the overall growth rate of the industry has slowed down significantly. The rapid growth of the top $10 \%$ platform is in stark contrast to the stable growth rate of the industry as a whole. In the context of slower growth in the industry, the top $10 \%$ platforms still maintain high growth rates, so we need to pay close attention to prevent the occurrence of explosive mines after false prosperity.

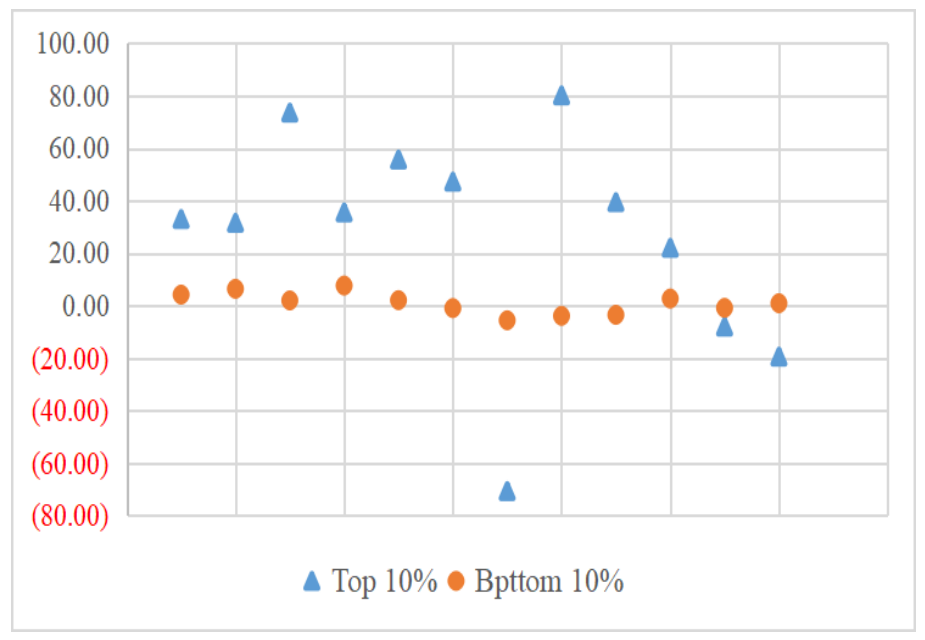

Figure 5: Comparison of Transaction Volume Growth 
International Journal of Social Science and Economic Research

ISSN: 2455-8834

Volume: 05, Issue: 01 "January 2020"

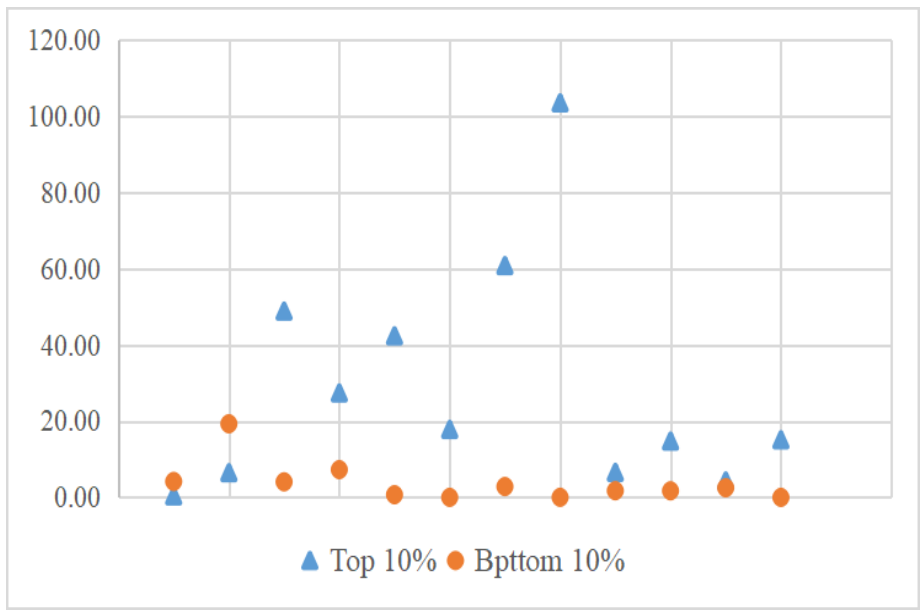

Figure 6: Comparison of Investor Growth

(3) In terms of operational risk, the platforms with a low concentration of the top 10 borrowers have a relatively high risk-return ratio. The proportion of the top 10 borrowers in the top $10 \%$ of the platform is relatively concentrated, with half of them exceeding $10 \%$ and one of them exceeding $80 \%$, which greatly increases the operating risk of the platform. The proportion of the bottom $10 \%$ of platforms is generally less than $10 \%$, mostly less than $5 \%$, with a high degree of capital dispersion (Figure7). By comparing the risk-return ratio, it can be found that the riskreturn ratio of the bottom $10 \%$ platform is higher than that of the top $10 \%$ platform as a whole, indicating that the bottom $10 \%$ platform takes higher leverage when obtaining yield per unit (Figure8). Combining the two indicators of operational risk, it is found that the bottom 10\% of platforms have a low concentration, while the overall leverage is relatively higher. This risk feature can be analyzed from the platform strength and risk control level, etc. The bottom $10 \%$ of platforms have stronger capital, more stable development and lower capital concentration, so they have higher risk control level and lower operational risk, so they are able to take more financial risks and higher leverage. 
International Journal of Social Science and Economic Research

ISSN: 2455-8834

Volume: 05, Issue: 01 "January 2020"

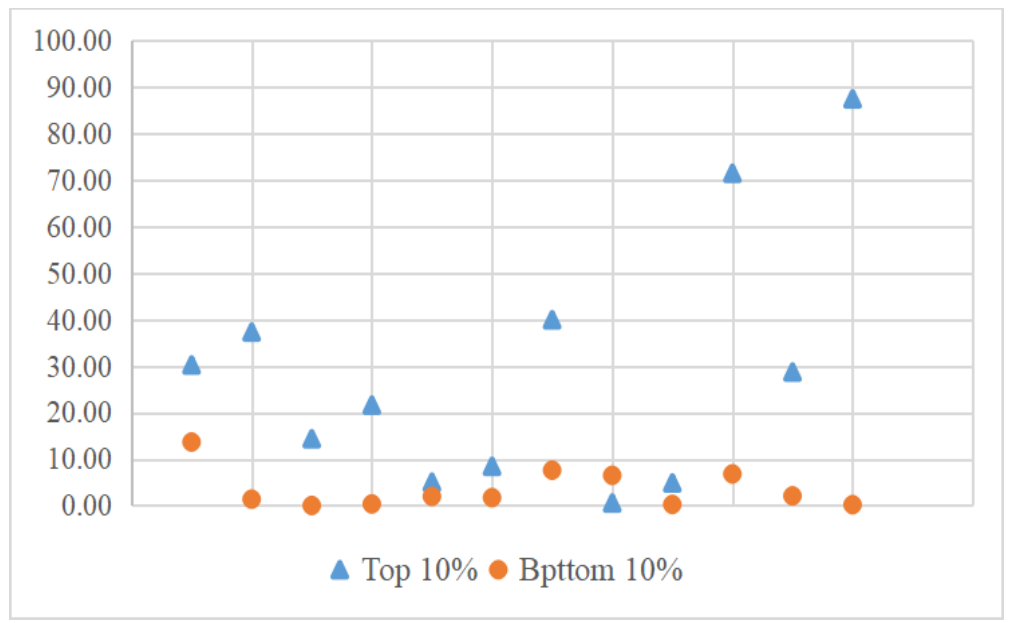

Figure 7: Comparison of Proportion of Top Ten Borrowers To Repay

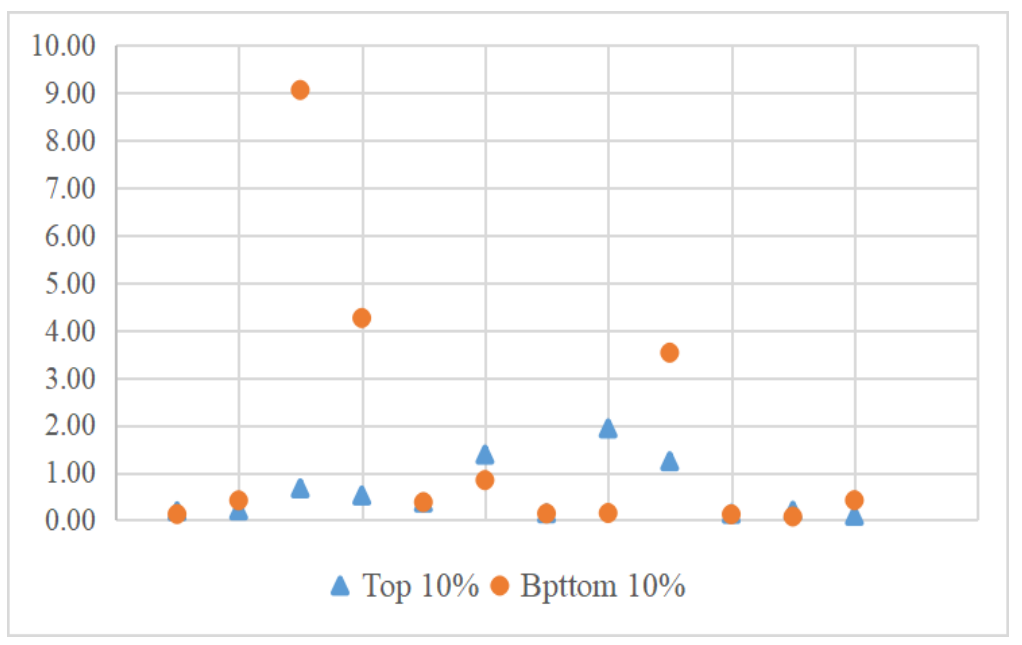

Figure 8: Comparison of Risk-return Ratio

(4) In terms of compliance degree, the compliance degree of the bottom $10 \%$ platform is better than that of the top $10 \%$. The bottom $10 \%$ of platforms all have bank depository, accounting for $100 \%$, while the top $10 \%$ have bank depository, accounting for only $58.3 \%$ (Figure9). It is difficult to guarantee whether the use of funds is safe and reasonable, and there is the possibility of the platform's own capital pool. To solve the problem, depository regulators publish relevant policy for many times. In February 2017, the CBRC issued the "network borrowing funds depository business guide". In December 2017, the regulatory authorities proposed that online lending institutions should cooperate with banking financial institutions in fund depository and management. In August 2018, the national mutual fund regulation office requires online lending institutions to strictly check whether the platform is strictly defined as information intermediary, 
whether there is a capital pool, etc. With the increasing regulation, platforms without existing management are bound to face compliance risk, or will be gradually cleaned up.

(5) In terms of liquidity, the overall net outflow trend of the top $10 \%$ platform funds is more significant. The ratio of capital flow to transaction value of the bottom $10 \%$ platform is -0.007 , while that of the top $10 \%$ platform is -0.013 , nearly twice that of the bottom $10 \%$ platform. The trend of net capital outflow is more obvious than that of the bottom 10\% platform (Figure10). Under the background of the growth of the whole industry is slowing, cash outflows also accord with the current environment. However, if the capital is in the state of net outflow for a long time, the liquidity risk of the platform will be greatly intensified. Therefore, it is necessary to keep an eye on the platform with a large net outflow of capital.

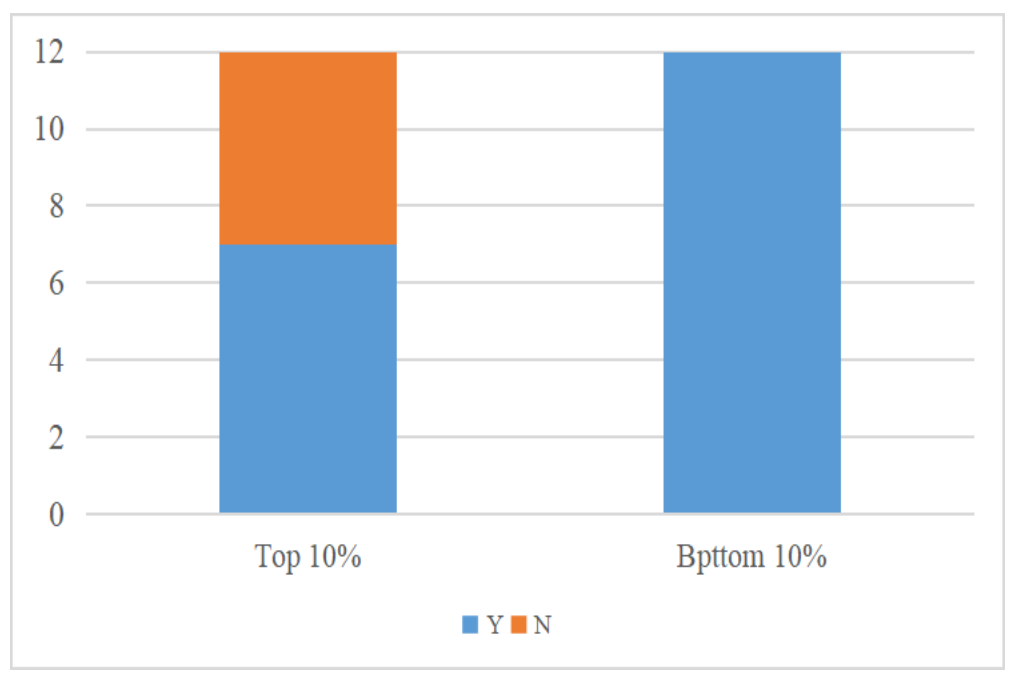

Figure 9: Comparison of Bank Deposit 


\section{International Journal of Social Science and Economic Research}

ISSN: $2455-8834$

Volume: 05, Issue: 01 "January 2020"

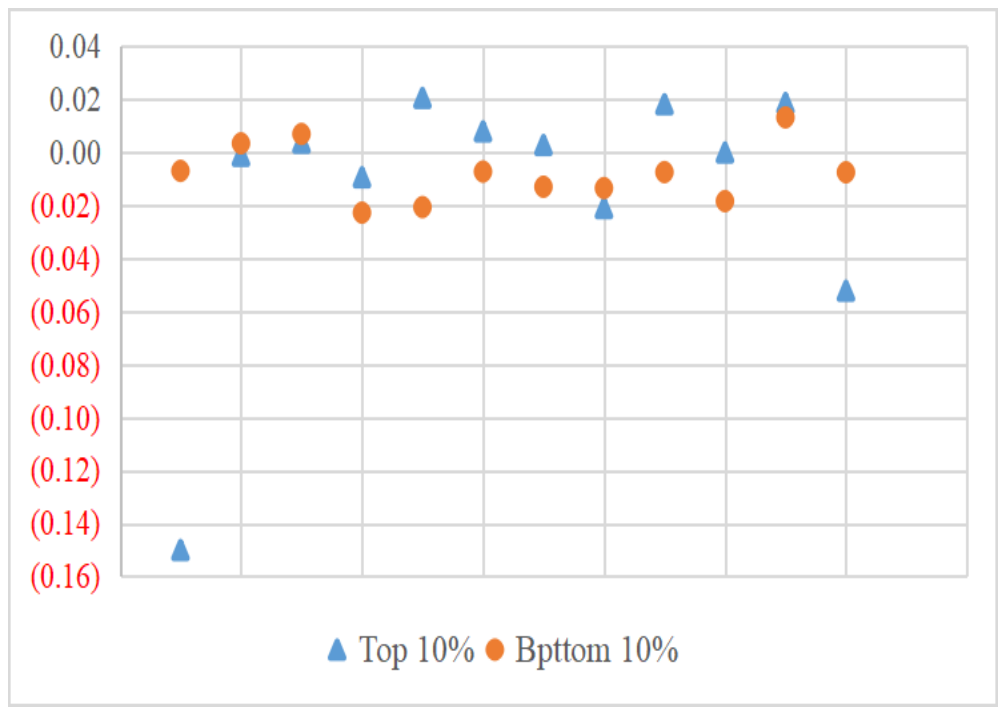

Figure 10: Comparison of Cash Flow

\subsection{Results Backtest}

The ultimate purpose of this paper is to provide regulators with a classification and disposal reference, so the model needs to be predictive to have practical significance. For the accuracy of the empirical results, the previous results were then backtested.

The research date of this paper is December 2018. As of June 2019, among the 123 public-data private platforms selected in this paper, a total of 5 new private platforms have been added, which are the yidiantongcaifu, youxicaifu, yonghejinrong, zhongxingcaifu and jiedaizhijia. In the conclusion of this paper, yidiantongcaifu is in the top 20\%, youxicaifu and yonghejinrong are in the top 30\%, and zhongxingcaifu and jiedaizhijia are in the top $40 \%$. Therefore, the latest problem platforms belong to the more dangerous platforms defined in this paper, with high prediction accuracy and practical reference significance.

Based on the analysis of the specific indicators and risk causes of the new problem platform (Table10), it is found that there are three main reasons, namely, rapid development deceleration, rapid and savage growth, and high leverage under the condition of insufficient strength. The platforms that slowed sharply were the yidiantongcaifu and ljiedaizhijia, with average growth rates of $-30 \%$ and $-55 \%$, respectively, and transaction volumes falling sharply. Zhongxingcaifu grows too fast and savagely, with a growth rate of up to 55\%, which is the opposite of the overall negative growth of the industry, suggesting the hidden worries behind its savage growth. Under the condition of insufficient strength, those who take high leverage are youxicaifu and yonghejinrong. Their registered capital is only 10 million yuan, but their leverage ratio is more 
International Journal of Social Science and Economic Research

ISSN: $2455-8834$

Volume: 05, Issue: 01 "January 2020"

than 10 times, which is at a high level in the industry. Therefore, the accuracy of the model is high in the backtesting of the problem platform, which proves that the model has certain practical significance.

Table 10: Detailed Indicator of New Problem Platforms

\begin{tabular}{|c|c|c|c|c|c|c|c|c|c|c|c|}
\hline Platform & Ranking & $\mathrm{X} 1$ & $\mathrm{X} 2$ & X3' & $\mathrm{X} 4^{\prime}$ & $\mathrm{X} 5$ & $\mathrm{X} 6$ & $\mathrm{X} 7$ & $\mathrm{X} 8$ & Leverage & Yield \\
\hline $\begin{array}{l}\text { yidiantong } \\
\text { caifu }\end{array}$ & 23 & 43 & 30 & -29.658 & -32.271 & 15.220 & 0.028 & 1 & -0.086 & 0.383 & 13.710 \\
\hline youxicaifu & 28 & 33 & 10 & 20.312 & 5.149 & 1.440 & 1.345 & 1 & 0.024 & 14.515 & 10.770 \\
\hline $\begin{array}{l}\text { yonghejin } \\
\text { rong }\end{array}$ & 31 & 55 & 10 & 13.268 & 0.570 & 5.240 & 1.899 & 1 & 0.008 & 20.997 & 11.060 \\
\hline $\begin{array}{c}\text { jiedaizhiji } \\
\text { a }\end{array}$ & 43 & 49 & 60 & -54.196 & -32.684 & 5.570 & 0.298 & 1 & 0.050 & 3.140 & 10.530 \\
\hline $\begin{array}{l}\text { zhongxing } \\
\text { caifu }\end{array}$ & 48 & 46 & 52 & 55.504 & 10.816 & 1.570 & 0.488 & 1 & 0.005 & 5.376 & 11.010 \\
\hline
\end{tabular}

\section{CONCLUSION AND PROSPECT}

This paper takes 123 private P2P platforms that have published complete data on wangdaizhijia as the research objects, determines the indicator weight by AHP-entropy weight method, and calculates and ranks the platform's relevance degree by using the grey relational model. In the risk assessment system of private P2P platforms constructed in this paper, the weight of registered capital is the highest. The registered capital of a platform is the financial support, and some large platforms with strong registered capital usually have higher risk control capacity. Therefore, regulators should pay close attention to this indicator when dealing with platforms, and pay attention to platforms with low registered capital. At the same time, high-risk platforms are characterized by insufficient platform strength, rapid and brutal development, low compliance level and long-term net cash outflow. Therefore, the regulators can give appropriate clearance to such platforms when classifying them. Based on the above research results, combined with the actual situation of $\mathrm{P} 2 \mathrm{P}$ platform development and supervision in China's private sector, the following policy suggestions are proposed.

(1) Classified disposal and avoid one-size-fits-all. Since 2019, regulators have been determined to rectify P2P platforms, encouraging most to quit. By November 2019, 18 provinces, cities and autonomous regions in China had published lists of P2P clearances, with varying degrees of 


\section{International Journal of Social Science and Economic Research}

ISSN: $2455-8834$

Volume: 05, Issue: 01 "January 2020"

strength and methods, but the general direction of the benign clearances was the same. The purpose of benign liquidation also means that the platform should be classified and disposed of to avoid one-size-fits-all disposal. Platforms that are out of contact or out of service should be banned, and the operating platforms should be persuaded to withdraw and transformed according to their risks, and properly handled after reasonable communication with the platforms.

(2) Focus on the platform registered capital in platform risk assessment. In the process of classified disposal, some platforms with strong comprehensive strength should be promoted to carry out transformation. Li junfeng, director of the inclusive finance department of the CBRC, also said that some institutions with strong capital strength, certain fintech foundation and good internal control ability should be encouraged to actively transfer to network small loan companies. In the indicator system of this paper, it is also concluded that the capital strength of the platform has the highest weight, and the capital of the platform is an important guarantee for risk prevention. Therefore, the regulator should focus on the important indicator in the platform risk evaluation and classified disposal.

(3) Refer to the multi-dimensional assessment system based on platform strength, growth ability, operational risk, compliance risk and liquidity risk. Platforms with low registered capital, brutal growth, high loan concentration, low compliance level and long-term net outflow of funds can be removed. Conversely, for a platform with strong strength, mature risk control and good operation, regulator should promote its transformation. At the same time, the follow-up of the platform with smooth transformation should also be subject to continuous supervision from these dimensions, so as to guard against new risks.

In addition, the time point selected in this paper is the data of 2018, and the static risk analysis is carried out, aiming to provide a reference for the indicator system and research methods for the risk assessment of the platform. In order to achieve more effective dynamic evaluation, the follow-up can continuously pay attention to the platform, especially the platform with higher correlation and higher potential risk, and continuously disclose the dynamic risk evaluation and rating of the platform, so as to analyze the risk situation of the platform more accurately.

\section{REFERENCES}

[1] Arrow, K.J(1994). The Economics of Information[M], Oxford: Basil Blackwell Limited.

[2] Jin, G Z(2008). Do Social Networks Solve Information Problems for Peer-to-Peer Lending? Evidence from Prosper.com. Seth Freedman[J], 2:8-43.

[3] Lin M, N, Prabhala and S. Viswanathan(2013). Judging Borrowers by the Company They Keep: Friendship Networks and Information Asymmetry in Online Peer-to-Peer Lending, Management Science[J], 59(1): 17-35. 


\section{International Journal of Social Science and Economic Research}

ISSN: $2455-8834$

Volume: 05, Issue: 01 "January 2020"

[4] Luo Sidan, Wang Ran(2014). Research on Strengthening the Supervision of P2P Risk in China, Economic Review Journal [J],9:28-31.

[5] Helfat (2007). Relational Capabilities: Drivers and Implications, In Dynamic Capabilities: Strategic Change in Organizations[M], 65-80.

[6] Angilella S.Harris(2015). The Financing of Innovative SMEs: A Multi-criteria Credit Rating Model, European Journal of Operational Research[J], 244: 45-49.

[7] Daniel Felix Ahelegbey, Paolo Giudici, Branka Hadji-Misheva(2019). Latent factor models for credit scoring in $\mathrm{P} 2 \mathrm{P}$ systems, Physica A: Statistical Mechanics and its Applications[J], 522:112-121.

[8] Eunkyoung Lee, Byungtae Lee(2012). Herding behavior in online P2P lending: An empirical investigation, Electronic Commerce Research and Applications[J], 11:495-503.

[9] Ye Qing, Li Zengquan, Xu Weihang(2016). A Risk Detection Study about Online P2P Lending Platforms, Accounting Research[J],6:38-45+95.

[10] Wu Yunke, Xu Mei(2017). Financial Risk Analysis and Countermeasures of P2P Platform,Finance Economy[J], 20:152-153.

[11] Barasinska(2009).On-line trust: Concepts, Evolving Themes,A Model, International Journal Human-Computer Studies[J],58(6):737-758.

[12] Everett C(2015). Group membership, Relationship Banking and Loan Default Risk:The Case of Online Social Lending,Banking and Finance Review $[\mathrm{J}], 7(2)$.

[13] Office, United States (2011). Person-to-Person Lending: New Regulatory Challenges Could Emerge as the Industry Grows, Government Accountability Office Reports[R].

[14] Yu Lin.Kang Canhua, Wang Long(2015). Study on Internet Financial Supervision Game:A Case Study of the P2P Net Loan Mode, Nankai Economic Studies[J], 5:126-139.

[15] Fang Xing(2018). Can Industry Association Promote the Sound Development of P2P Online Lending? Contemporary Finance \& Economics[J], 7:57-68.

[16] [16] Pan Jing(2018).Perfection of the Internet Financial Regulatory Rules Considering the United States and Britain as Mirror,Journal of Hebei University of Economics and Business[J],39(02):63-70.

[17] Jiang Zhiyuan, Wang Lizhao(2019). The Study of Competitiveness Evaluation System of P2P Lending Platforms — Based on the Improved CRITIC-GRAP Model, Chinese Journal of Systems Science[J], 3:60-65.

[18] Wang Liyong, Shi Ying(2016). Risk Mechanism and Risk Evaluation of Internet Finance:A Case Study of P2P Net loan, Journal of Southeast University(Philosophy and Social Science)[J]. 18(02):103-112+148.

[19] Guo Haifeng, Chen Xiao(2015). A Study of the Comprehensive Competitiveness Evaluation of P2P Network Lending Platform, Financial Forum [J], 20(02):12-23. 